\title{
H. B. Reitlinger and the origins of the Efficiency at Maximum Power formula for Heat Engines
}

\author{
A. Vaudrey*, \\ F. Lanzetta $a^{\ddagger}$ \\ M. Feidt ${ }^{\S}$
}

October 23, 2014

\begin{abstract}
Even if not so ancient, the history of the heat engine efficiency at maximum power expression have been yet turbulent. More than a decade after the publication of the seminal article by CURzon and AHLBORN in 1975, one's rediscovered two older works by CHAMBADAL and NoviKov, both dating from 1957. Then, some years ago, the name of Yvon arose from a textual reference to this famous relation in a conference article published in 1955. Thanks to an historical study of French written books not anymore published for a long time, and since never translated in other languages, we bring to light in this paper that this relation was actually firstly proposed by HenRi B. Reitlinger in 1929.
\end{abstract}

\section{Introduction}

The heat engine efficiency at maximum power formula is probably the most famous and important one of modern technical thermodynamics. It pushed the latter out of the fetters of strictly equilibrium configurations, and then closer to behaviors of actual systems, and gave birth to what is called now the Finite Time Thermodynamics (FTT), [1, 2]. However, besides its own physical meaning, its recent but lively history could say a lot about the sometimes sinuous path of science.

In this paper, thanks to the study of not anymore published for a long time French written books, we will come back to the root of this formula. We will follow its interesting story, up to its first publication in 1929, by HenRi B. Reitlinger. The goal is here to render unto Caesar that which is Caesar's in giving to HenRI ReITlinger the place he deserves in the history of thermodynamics.

\section{A short history of the efficiency at maximum power for- mula}

Curzon and Ahlborn, 1975 Most of the references dealing with the thermal efficiency at maximum power of a reversible heat engine operating between cold and hot heat reservoirs respectively at temperatures $T_{\text {cold }}$ and $T_{\text {hot }}$, i.e. :

$$
\eta_{\mathrm{opt}}=1-\sqrt{\frac{T_{\mathrm{cold}}}{T_{\text {hot }}}}
$$

cites the seminal article of CURzon and AhLBorn [3], published in 1975.

This article presented a theoretical analysis of the fundamental Carnot cycle, but with each of its two isothermal heat exchange processes occurring in finite time, [4]. One of the most impressive

\footnotetext{
${ }^{*}$ Corresponding author : alexandre.vaudrey@ecam.fr

${ }^{\dagger}$ University of Lyon, ECAM, Energy Laboratory, 40 monte Saint Barthlemy, 69321 Lyon, France.

${ }^{\ddagger}$ University of Franche-Comte, FEMTO-ST, UMR CNRS 6174, Parc technologique, 2 av. Jean Moulin, 90000 Belfort, France.

$\S$ University of Lorraine, Laboratory of Energetics \& Theoretical \& Applied Mechanics, 2 av. de la Forêt de Haye, 54518 Vandœuvre-lès-Nancy, France.
} 
aspects of relation (1) is its complete independence on the specific characteristics of concerned engine, exactly as for the well known Carnot's formula. This fascinating result was the starting point of the Finite Time Thermodynamics [1]. Since then and during more than two decades, $\eta_{\mathrm{opt}}$ of relation (1) was fairly called CURZON-AHLBORN efficiency, often noted $\eta_{\mathrm{CA}}$.

Chambadal and Novikov, 1957 In at least two articles, BEJAN $[5,6]$, previously warned by one of us [7], reminded to the scientific community that relation (1) was actually published almost two decades before the CURzon and AHLBORN paper, separately by two different authors : CHAMBADAL [8] and Novikov [9]. The Novikov's article was actually published in Russian in 1957, the same year as the CHAMBADAL's book, but translated in English one year later. Both studies were devoted to nuclear energy, the first one considering a Carnot reversible engine fed in heat by a finite capacitance stream and the second one more focusing on the thermodynamic cycle itself, see [6]. Even if some authors [10] have recently expressed doubts about the CHAMBADAL's paternity on relation (1), mainly because of a different model than the Novikov one, we insist on the identity of both results. The aim of both studies is the same : to maximize the useful effect of heat engines, whether this effect is expressed as work or power.

Bejan then proposed to call the concerned efficiency (1) "Chambadal-Novikov-CurzonAHLBORN efficiency", and to note it $\eta_{\mathrm{CNCA}}$. Surprisingly, many authors still neglect this important historical update and often cite in recent papers only reference [3].

Yvon, 1955 More recently, Moreau et al [11], working on the specific situation of maximum power production by thermal engines, cited a conference article published by JACQUES YvON [12] in 1955, two years before the CHAMBADAL and NOviKOv publications, and containing the following strange because of harmless quotation :

"Without specifying the thermal power at which the reactor must operate, the mean fluid temperature can be chosen so that the usable power be as large as possible. The result is that it must be the geometric mean of the [high and low] temperatures [...]"

so exactly the approach leading to equation (1).

Even if the concerned conference was probably not dedicated to thermodynamics or heat engines, but rather to nuclear reactor science, such casual statement is disturbing because seemingly obvious for the author, as if it was a widely known and accepted result. Unfortunately, publication [12] made no reference to previous work on this topic and leads to a dead-end for historical research.

The only way remaining to investigate on the story of formula (1) seemed to be contained in one of the books about thermodynamics published by Paul Chambadal. Sadly, none of these were translated in an other language than French, which could partly explain the lack of spreading of results we will discuss about in the rest.

Chambadal, 1949 Indeed, in a book published in 1949 and dedicated to thermodynamics of gas turbines, Chambadal [13] yet studied configurations of maximum produced work by such system, and obtained relation (1) and others resulting from it, even if in a slightly different way. On figure 1 is presented a picture taken from the page 225 of the CHAMBADAL's book [13] from 1949, containing among others the famous relation between optimal temperature $T_{2, \text { opt }}$ and corresponding cold and hot ones $T_{1}$ and $T_{3}$. This relation naturally leads the author to obtain efficiency (1) in following pages. Fortunately, Chambadal cites as reference (on the footnote of figure 1) a previous book on this topic, published by Henri B. ReItlinger in 1930.

\section{The Reitlinger book}

The concerned book, firstly published by Henri B. Reituinger [14] in 1929 was dedicated to practical designs and uses of heat engines, at this time often driven by the combustion of coal. Such system was considered by the author as open, and composed by a heat to work conversion device exchanging heat with hot and cold fluids thanks to heat exchangers, as presented on figure 2. Heat exchangers A-A' and B-B' are respectively used to feed the work conversion device $\mathrm{C}$ with a 
du taux de compression. La valeur optimum de $z$ sera donc donnée ici par (116), soit, avec les hypothèses et notations adoptées :

d'où :

$$
z_{\text {opt. }}=\sqrt{\frac{\mathrm{T}_{3}}{\mathrm{~T}_{1}}}
$$

Il en résulte que :

$$
\mathrm{T}_{2 \text { opt. }}=\mathrm{T}_{4 \text { opt. }}=\sqrt{\mathrm{T}_{1} \mathrm{~T}_{3}}
$$

$$
q_{u_{\max .}}=c_{p}\left(\mathrm{~T}_{3}-z \sqrt{\mathrm{T}_{1} \mathrm{~T}_{3}}+\mathrm{T}_{1}\right)=c_{p}\left(\sqrt{\mathrm{T}_{3}}-\sqrt{\mathrm{T}_{1}}\right)^{2} .
$$

Comme, d'autre part, la chaleur dégagée par la combustion est donnée par $c_{p}\left(\mathrm{~T}_{3}-\mathrm{T}_{1}\right)$ calories par kilogramme de gaz, le rapport $\eta_{1}$ de $q_{u_{\max }}$ au pouvoir calorifique du combustible, c'est-à-dire le coefficient d'utilisation de la chaleur pour le cycle considéré, est donné par :

$$
\eta_{1}=\frac{\left(\sqrt{\mathrm{T}_{3}}-\sqrt{\mathrm{T}_{1}}\right)^{2}}{\mathrm{~T}_{3}-\mathrm{T}_{1}}
$$

Cette expression est identique à celle qu'on obtient (1) dans l'hypothèse d'un fluide auxiliaire décrivant un cycle de Carnot

(1) Voir H. B. ReITLINGER: L'utilisation de la chaleur dans les machines à feu (éd. Béranger, Paris, 1930).

Figure 1: Extract from CHAMBADAL's book [13, page 225] published in 1949 and yet containing some equations nowadays related to Finite Time Thermodynamics. One could also notice the footnote with reference to the edition of the REITLINGER's book published in France in 1930, so one year later the Belgian first one.

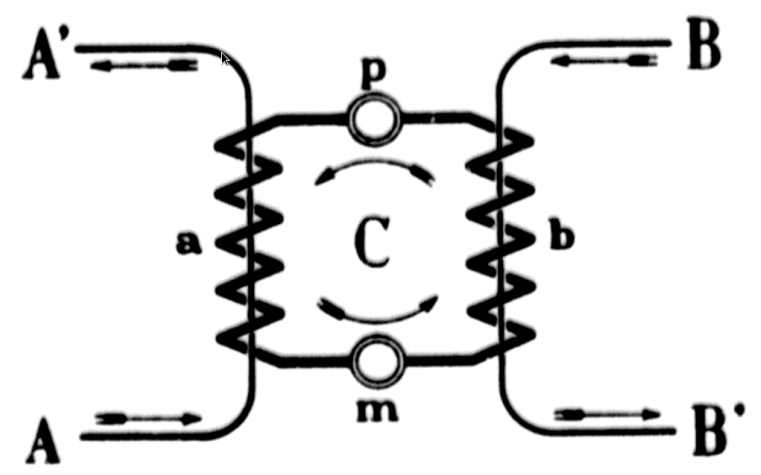

F16. 1

Figure 2: Representative figure of a heat engine considered as an open system, hot stream entering in A and exiting in A', the B-B' circuit being dedicated to cold stream. The heat to work conversion device is here indicated by letter $\mathrm{m}$ (for machine) and represented by circuit noted C. $a$ and $b$ are respectively the hot and cold heat exchangers and $\mathrm{p}$ the pump of the primary circuit [14, page 12].

hot stream produced by a combustion process, and expel the remaining cold heat to surroundings thanks to e.g. a liquid water cooling system.

Describing heat engines operating principle in this way naturally leads to consider the need of temperature differences within each hot and cold streams, in order to exchange heat with C, the heat-to-work conversion part of the system. REITLINGER logically studied the impact of such temperature differences on the performance of the whole system, and obtained in first the relation (1), as presented on the bottom of figure 3. Even non French readers could clearly notice the 
on voit qu'il est constamme.st positif. Sa valeur maxima a lieu pour la valeur de $t$ qui annule la dérivée, et l'on trouve ainsi que ce maximum a lieu pour une certaine valeur optima de $\mathbf{t}$ que je désigne par $t_{3}$ et qui est :

$$
t_{0}=\sqrt{T_{1} T_{2}}
$$

Substituant à la place de $\mathbf{t}$ cette valeur $\mathbf{t}_{0}$ dans l'expression du travail, on trouve après réduction et simplification :

$$
\widetilde{\sigma}_{\max }=\mathbf{E} Q \frac{\left(\sqrt{T_{1}}-\sqrt{T_{2}}\right)^{2}}{T_{1}-T_{2}}
$$

V. Telle serait la valeur maxima de l'énergie mécanique susceptible d'être recueillie au moyen d'un cycle de Carnot entre une source chaude payée dont la température d'entrée serait $\mathbf{T}_{1}$ et une source froide gratuite dont la température serait celle de l'ambiance $\mathbf{T}_{2}$. On voit que le coefficient d'utilisation global de l'ensemble du cycle et des sources pour ce cycle optimum est représenté par :

$$
U_{\max .}=\frac{\left(\sqrt{T_{1}}-\sqrt{T_{2}}\right)^{2}}{T_{1}-T_{2}}
$$

Il est intéressant de voir comment interviennent dans ce coefficient d'utilisation global optimum les deux facteurs qui le caractérisent, à savoir le coefficient d'utilisation de la source payée $(u)$ et le coefficient d'utilisation du cycle, autrement dit sa fraction disponible $(\eta)$. On trouve ainsi, en substituant pour ( $t)$ dans les expressions respectives la valeur $\left(t_{0}\right)$ qui vient d'être calculée, correspondant au maximum du travail :

- pour le coefficient d'utilisation de la source :

$$
u_{0}=\sqrt{T_{1}} \frac{\sqrt{T_{1}}-\sqrt{T_{2}}}{T_{1}-T_{2}}
$$

- pour la fraction disponible du cycle :

$$
\eta_{0}=\frac{V T_{1}-V T_{2}}{V T_{1}}
$$

Figure 3: Page of the ReITLINGER's book [14, page 28] presenting yet in 1929 the expressions of temperatures, produced work and relating efficiency of a heat engine operating at maximum power configuration. The last equation at the bottom of the page is actually the first one in history about the efficiency at maximum power.

expressions of optimal temperature $t_{0}=\sqrt{T_{1} \cdot T_{2}}$ of the exhaust hot stream, defined as previously explained as the geometric mean of hot and cold entrance temperatures of stream, respectively noted $T_{1}$ and $T_{2}$. On figure 2 , hot stream composed by coal combustion exhaust gas enters in A at temperature $T_{1}$ and exits in $\mathrm{A}^{\prime}$ at temperature $t$.

In the case presented on figure 3, cold heat exchanger between points B and B' is supposed isothermal at temperature $T_{2}$, thanks to an almost infinite thermal flow $\dot{m} \cdot c_{p}$ of liquid water, regarding to the hot one composed by combustion exhaust gas flow.

We can notice that CHAMBADAL [8] applied exactly the same calculation on a steam turbine in his 1957's book about nuclear power plants.

Replacing hot exit temperature $t$ by its optimal value $t_{0}$, REITLINGER obtained the second 
equation on picture 3, related to the maximum amount of work such engine could produce. Finally, when interested by the thermal efficiency expression, he obtained for the first time the formula (1), written as :

$$
\eta_{0}=\frac{\sqrt{T_{1}}-\sqrt{T_{2}}}{\sqrt{T_{1}}}
$$

as presented on the bottom of figure 3 .

\section{Conclusion}

History of science is well known to not be a long and quiet river. Historical studies sometimes remind to the scientific community the names of scientists that firstly proposed theories, which became later famous without the name of their original creators. From time to time, a concept has been discovered and developed by several scientists at the same time and just few of them have let their name on the resulting theory. The "BETz limit" of produced power by propellers or wind turbine is a typical example of that [15].

More rarely, the concerned concept or theory have been published a long time before, within a different scientific domain or in another language, and had never been translated since. This is probably what happened for the heat engine efficiency at maximum power, which was actually published almost half a century before the most often cited paper from CuRzon and AHLBorn. This fact obviously doesn't withdraw any virtue from these authors and doesn't cast any doubt on their fundamental contribution to the creation of Finite Time Thermodynamics. With the historical perspective, the result they obtained appears as a brilliant completion of a thought process started a long time before, thanks to more specific and practical purpose. Finally, it emphasize the fundamental importance of scientific information spreading, of collaborations between scientists reading different languages and of historical studies once in a while.

\section{Acknowledgments}

Authors want to thank the Bibliothèque nationale de France $(\mathrm{BnF})$ for the digitizing of the REITLINGER's book, that allowed the present study and paper.

\section{References}

[1] R. S. Berry. Finite-Time Thermodynamics, pages 131-146. Springer series in chemical physics, 2008.

[2] B. Andresen. Current trends in finite-time thermodynamics. Angewandte Chemie International Edition, 50(12):2690-2704, 2011.

[3] F. L. Curzon and B. Ahlborn. Efficiency of a Carnot Engine at Maximum Power Output. American Journal of Physics, 43:22-24, 1975.

[4] A. De Vos. Efficiency of some heat engines at maximum-power conditions. American Journal of Physics, 53(6):570-573, 1985.

[5] A. Bejan. Engineering Advances on Finite-Time Thermodynamics. American Journal of Physics, 62(1):11-12, 1994.

[6] A. Bejan. Entropy generation minimization : The new thermodynamics of finite-size devices and finite-time processes. Journal of Applied Physics, 79(3):1191-1218, 1996.

[7] M. Feidt. Thermodynamique et Optimisation Énergétique des Systèmes et Procédés ("Thermodynamics and Energy Optimization of Systems and Processes", in French). Lavoisier, 1987.

[8] P. Chambadal. Les centrales nucléaires ("Nuclear plants", in French). A. Colin, Paris, 1957. 
[9] I. J. Novikov. The efficiency ot atomic power stations. J. Nuclear Energy, 7(2):125-128, 1958.

[10] Y. Apertet, H. Ouerdane, C. Goupil, and Ph. Lecoeur. Efficiency at maximum power of thermally coupled heat engines. Physical Review E, 85(4):041144, 2012.

[11] M. Moreau, B. Gaveau, and L. S. Schulman. Stochastic dynamics, efficiency and sustainable power production. The European Physical Journal D-Atomic, Molecular, Optical and Plasma Physics, 62(1):67-71, 2011.

[12] J. Yvon. The Saclay Reactor : Two years experience on heat transfer by means of compressed gas. In Proceedings of the International Conference on Peaceful Uses of Atomic Energy, page 387, Geneva, Switzerland, 1955. United Nations.

[13] P. Chambadal. Thermodynamique de la Turbine à Gaz ("Thermodynamics of the Gas Turbine”, in French). Hermann \& $\mathrm{C}^{\mathrm{ie}}, 1949$.

[14] H. B. Reitlinger. Sur l'utilisation de la chaleur dans les machines à feu ("On the use of heat in steam engines", in French). Vaillant-Carmanne, Liège, Belgium, 1929.

[15] G. A. M. van Kuik. The Lanchester-Betz-Joukowsky limit. Wind Energy, 10(3):289-291, 2007. 